\title{
Effect of yield stress on fatigue crack growth
}

\author{
M.F. Borges, F.V. Antunes, P. Prates, R. Branco, M.C. Oliveira \\ University of Coimbra, Portugal \\ micalfriasborges@outlook.pt \\ fernando.ventura@dem.uc.pt, bttp:/ /orcid.org/0000-0002-0336-4729 \\ pedro.prates@dem.uc.pt,ricardo.branco@dem.uc.pt,marta.oliveira@dem.uc.pt
}

\begin{abstract}
Fatigue crack growth (FCG) depends on loading, geometry and also material properties. Since FCG is supposedly linked to crack tip plastic deformation, material's yield stress, $\mathrm{Y}_{0}$, is an important parameter. The main objective here is to develop a parametric study focused on the effect of $Y_{0}$ on FCG. The study is based on the plastic CTOD, $\delta_{\mathrm{p}}$, determined numerically using the finite element method. The increase of $Y_{0}$ was found to decrease $\delta_{\mathrm{p}}$, and therefore FCG rate. The variation is non-linear, being more important for lower values of $\mathrm{Y}_{0}$. The effect of $\mathrm{Y}_{0}$ was found to be much more relevant for the 7050 aluminium alloy than for the 304L stainless steel, which indicated a major influence of isotropic saturation stress. With the inclusion of crack closure, the reduction of $\delta_{\mathrm{p}}$ is kept, but there is a substantial reduction of $\delta_{\mathrm{p}}$ and therefore of FCG rate.
\end{abstract}

\section{OPEN ACCESS}

Citation: Borges, M.F., Antunes, F.V., Prates, P., Branco, R., Oliveira, M.C., Effect of yield stress on fatigue crack growth, Frattura ed Integrità Strutturale, 50 (2019) 919.

Received: 24.05.2019

Accepted: 01.07.2019

Published: 01.10.2019

Copyright: (C) 2019 This is an open access article under the terms of the CC-BY 4.0, which permits unrestricted use, distribution, and reproduction in any medium, provided the original author and source are credited.

KEYwORDS. Fatigue Crack Growth; Plastic CTOD; Yield stress; Crack closure.

\section{INTRODUCTION}

$\mathrm{F}$ atigue Crack Growth (FCG) greatly depends on material parameters, however most of the studies are related to loading and geometrical parameters. Studies based on material parameters are less common in literature due to the difficulty of implementing parametric experimental tests because the parameters cannot be changed one by one. Also, the numerical tools available are typically devoted to studying the effect of loading parameters. This article is centered on the study of the effect of yield stress on FCG, using a numerical approach. Since FCG is related to non-linear and irreversible phenomena acting at the crack tip, it makes sense that the yield stress is an important parameter.

The methodology proposed by Antunes et al., based on plastic CTOD, was used to develop this parametric study [1]. This approach is based on the assumption that FCG is linked to crack tip plastic deformation, and that the plastic CTOD quantifies this deformation. The plastic CTOD includes crack closure in a natural way and excludes the elastic deformation, which is not expected to contribute to FCG. 
Numerical MODEL

7 o study the effect of the yield stress on FCG, two materials were considered: the 7050-T6 aluminium alloy (AA) and the 304L stainless steel (SS). To avoid the influence of geometry and loading, the same CT specimen (see Fig. 1) and loading conditions were used. The specimen had a width, $W$, of $50 \mathrm{~mm}$, an initial crack length, a o, of 24 $\mathrm{mm}$, therefore $\mathrm{a}_{0} / \mathrm{W}$ is 0.48 . To reduce numerical effort and since the specimen in question is symmetric relatively to two planes, only $1 / 4$ of the specimen was considered. Also to reduce the numerical effort, only a $0.1 \mathrm{~mm}$ of the thickness of the specimen was modelled. Adequate boundary conditions were implemented to reproduce the symmetry of the specimen and state of stress. Fig. 1b shows a lateral view of the specimen with symmetry conditions for plane stress state. For plane strain state an additional out of plane condition was implemented to avoid deformation along the thickness direction. The load was applied at the hole of the specimen and varied between $4.167 \mathrm{~N}$ and $41.67 \mathrm{~N}$, therefore the load ratio was $\mathrm{R}=0.1$ and $\mathrm{K}_{\max }, \mathrm{K}_{\min }$ and $\Delta \mathrm{K}$ were $18.3 ; 1.83$ and $16.5 \mathrm{MPa} . \mathrm{m}^{0.5}$, respectively.

\begin{tabular}{|c|c|c|c|c|c|c|c|}
\hline \multirow[t]{3}{*}{ Material } & \multicolumn{2}{|c|}{ Hooke’s law } & \multicolumn{3}{|c|}{ Voce law } & \multicolumn{2}{|c|}{$\begin{array}{c}\text { Armstrong-Frederick } \\
\text { law }\end{array}$} \\
\hline & E & $\nu$ & $\mathrm{Y}_{0}$ & $\mathrm{Y}_{\mathrm{Sat}}$ & $\mathrm{C}_{\mathrm{Y}}$ & $C_{X}$ & $\mathrm{X}_{\mathrm{Sat}}$ \\
\hline & [GPa] & {$[-]$} & {$[\mathrm{MPa}]$} & {$[\mathrm{MPa}]$} & {$[-]$} & {$[-]$} & {$[\mathrm{MPa}]$} \\
\hline \multicolumn{8}{|l|}{ AA7050-T6 } \\
\hline Reference & & & 420.50 & 420.50 & & & \\
\hline $0.50 \mathrm{Y}_{0}$ & & & 210.25 & 210.25 & & & \\
\hline $0.75 \mathrm{Y}_{0}$ & 71.70 & 0.33 & 315.38 & 315.38 & 0 & 228.91 & 198.35 \\
\hline $1.25 \mathrm{Y}_{0}$ & & & 525.63 & 525.63 & & & \\
\hline $1.50 \mathrm{Y}_{0}$ & & & 630.75 & 630.75 & & & \\
\hline \multicolumn{8}{|l|}{ SS304L } \\
\hline Reference & & & 117 & & & & \\
\hline $0.50 \mathrm{Y}_{0}$ & & & 58.50 & & & & \\
\hline $0.75 \mathrm{Y}_{0}$ & 196 & 0.30 & 87.75 & 204 & 9 & 300 & 176 \\
\hline $1.25 \mathrm{Y}_{0}$ & & & 146.25 & & & & \\
\hline $1.50 \mathrm{Y}_{0}$ & & & 175.50 & & & & \\
\hline
\end{tabular}

Table 1: Material parameters used in the analysis of the effect of the yield stress on fatigue crack growth.

The mechanical behavior of the materials was assumed to be elastic-plastic. The isotropic elastic domain was defined by the generalized Hooke's law elastic parameters Young's modulus (E) and Poisson's ratio (v). The plastic behavior was described by von Mises yield criterion coupled with a mixed hardening model using Voce isotropic and ArmstrongFrederick kinematic hardening laws, under an associated flow rule. Voce isotropic hardening law is given by:

$$
\mathrm{Y}\left(\bar{\varepsilon}^{\mathrm{p}}\right)=\mathrm{Y}_{0}+\left(\mathrm{Y}_{\mathrm{Sat}}-\mathrm{Y}_{0}\right)\left[1-\exp \left(-\mathrm{C}_{\mathrm{Y}} \bar{\varepsilon}^{\mathrm{p}}\right)\right]
$$

where $\mathrm{Y}_{0}, \mathrm{Y}_{\mathrm{Sat}}$, and $\mathrm{C}_{\mathrm{Y}}$ are the material parameters of Voce law and $\bar{\varepsilon}^{\mathrm{p}}$ is the equivalent plastic strain. The ArmstrongFrederick kinematic hardening law can be written:

$$
\dot{\mathrm{X}}=\mathrm{C}_{\mathrm{X}}\left[\frac{\mathrm{X}_{\mathrm{sat}}}{\bar{\sigma}}\left(\sigma^{\prime}-\mathrm{X}\right)-\mathrm{X}\right] \dot{\bar{\varepsilon}}^{\mathrm{p}}
$$


where $\mathrm{C}_{\mathrm{X}}$ and $\mathrm{X}_{\mathrm{Sat}}$ are the material parameters, $\bar{\sigma}$ is the equivalent stress and $\dot{\bar{\varepsilon}}^{\mathrm{p}}$ is the equivalent plastic strain rate. Tab. 1 shows the values of reference of the elastic-plastic properties discussed before and the variations made in the yield stress. The material constants for the 7050-T6 aluminium alloy and for the 304L stainless steel were obtained in previous works of the authors [2,3]. Variations of $+50 \%,+25 \%,-25 \%$ and $-50 \%$ were considered relatively to the references values. The AA7050-T6 has a pure kinematic behavior, therefore the variation of $\mathrm{Y}_{0}$ was accomplished by the variation of the saturation value $\left(\mathrm{Y}_{\mathrm{sat}}\right)$. On the oher hand, for the $304 \mathrm{~L}$ stainless steel only $\mathrm{Y}_{0}$ was changed, since the saturation value is always above $Y_{0}$.

The finite element mesh, illustrated in Fig. 1a, comprised 7287 3D linear isoparametric elements and 14918 nodes. At the crack tip, the mesh was refined with square elements that had $8 \times 8 \mu \mathrm{m}^{2}$ to simulate strain gradients and local stress. A coarser mesh was used in the remaining volume of the body to reduce computational overhead. Along the thickness, only one layer of elements was used. Crack propagation was simulated by successive debonding at minimum load of both current crack front nodes. Two load cycles were applied between each crack increment corresponding to one finite element. A total number of 320 load cycles were performed, corresponding to a crack advance of $\Delta \mathrm{a}=\left(\frac{320}{2}-1\right) \times 8=1272 \mu \mathrm{m}$, since in the first block there was no crack propagation. To eliminate crack closure phenomenon, in some numerical simulations the contact of crack flanks was removed. This permits the study of the effect of $\mathrm{Y}_{0}$ without the interference of crack closure phenomenon. The three-dimensional finite element software used to implement the numerical model was the DD3IMP in-house code, originally developed to simulate sheet metal forming processes [4-6]. This software takes into account large elastic-plastic deformations and rotations and assumes that the elastic strains are negligibly small with respect to unity. To simulate friction contact, the software uses the augmented Lagrangian method. The nonlinear system obtained is solved with the Newton-Raphson method. The contact of the crack flanks is modeled considering a rigid body (plane surface) aligned with the crack symmetry plane.

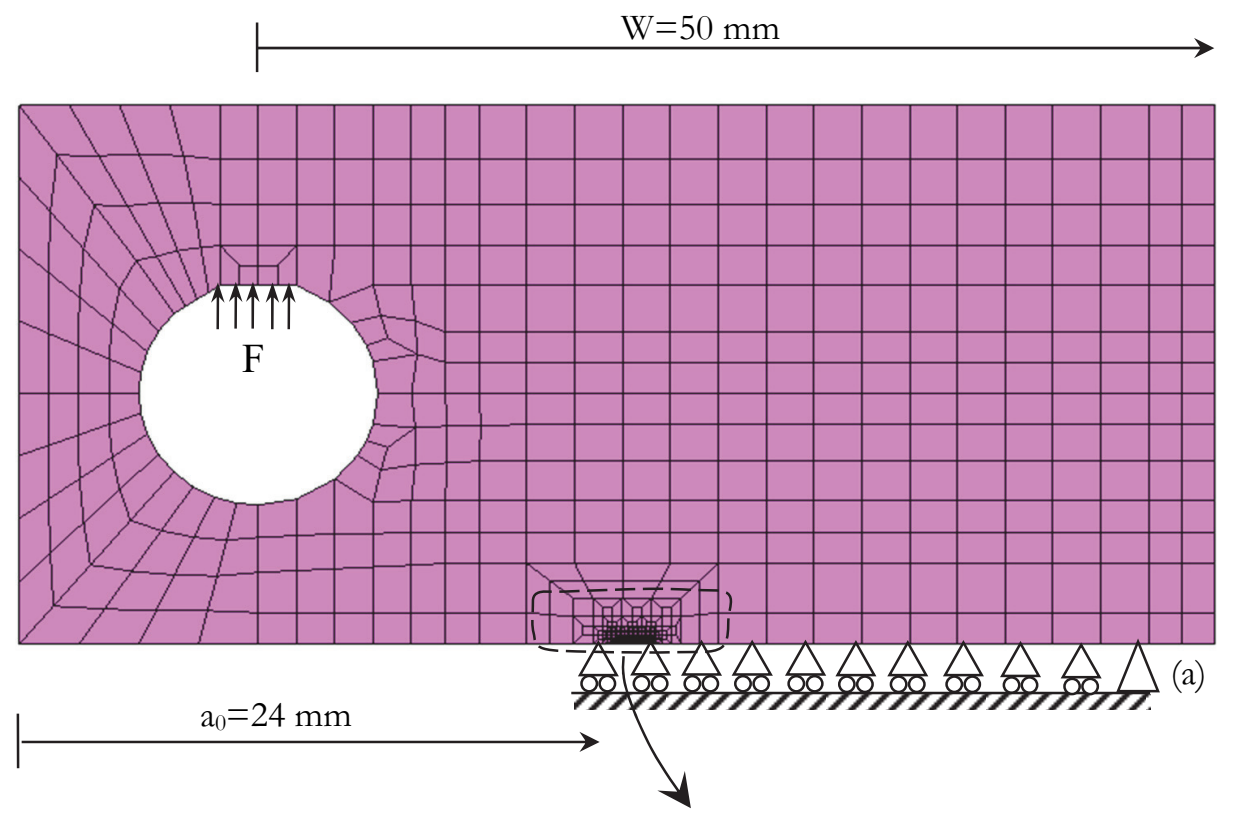

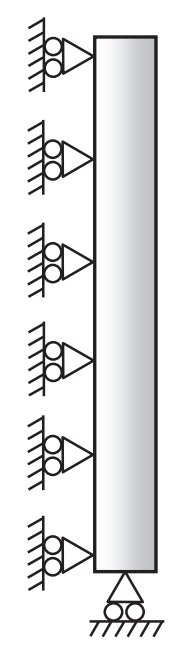

(b)

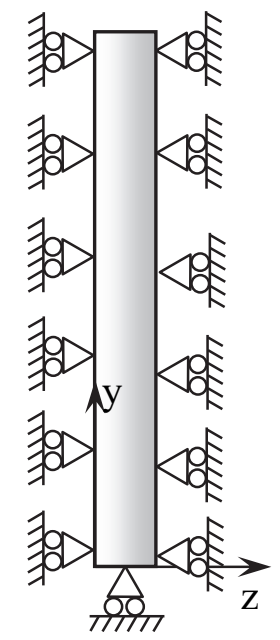

(c)

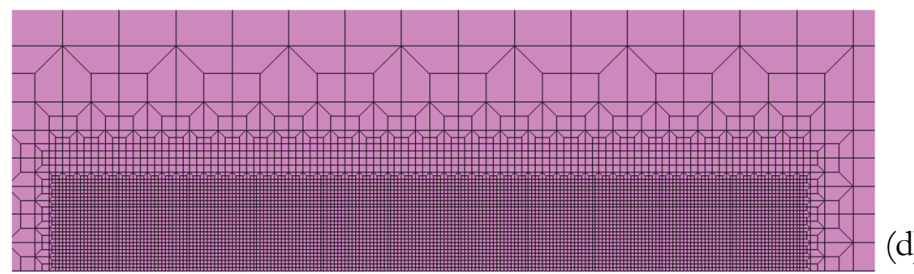

(d)

Figure 1: Model of the $\mathrm{C}(\mathrm{T})$ specimen. (a) Load and boundary conditions. (b) Boundary conditions for plane stress state. (c) Boundary conditions for plane strain state. (d) and (e) Details of finite element mesh. 


\section{RESULTS}

Typical CTOD curves

7 ig. 2a plots a typical curve of CTOD versus the force applied on the specimen made of AA7050-T6 in a numerical 1 simulation with contact at the crack flanks. It is noteworthy that the measuring of CTOD was performed at the first node behind the tip because it is the node that better illustrates the behavior at the tip. This curve was obtained after a crack growth of $1.272 \mathrm{~mm}$, corresponding to 159 crack increments of $8 \mu \mathrm{m}$ each. The simulation starts at point 1 , and between stretch 1-2 the CTOD is equal to zero, although the continuous increase of applied load, which means that the crack is closed during this range of load. At point 2, the crack opens and exhibits an elastic behavior between points 2 and 3. In this stretch, CTOD increases linearly with the load and only occurs elastic deformation at the tip. Point 3 is defined as the transition of elastic-plastic behavior. In this paper, the transition was assumed to occur for a plastic CTOD equal to $0.001 \mu \mathrm{m}$. When the tip enters the plastic regime, the linear increase of CTOD is no longer observed. Point 4 , is the point where the load reaches its maximum value and also corresponds to the point where the displacement at the tip is maximum. After point 4, the discharge begins and the linear behavior characteristic of elastic deformation is again observed, until point 5 , with a slope identical to the one previously verified. Between stretch 5 and 6 , occurs reversed plastic deformation and at point 6 CTOD reaches zero, which means that the crack closes. The total range of elastic and plastic deformation are marked as $\delta_{\mathrm{e}}$ and $\delta_{\mathrm{p}}$, respectively.
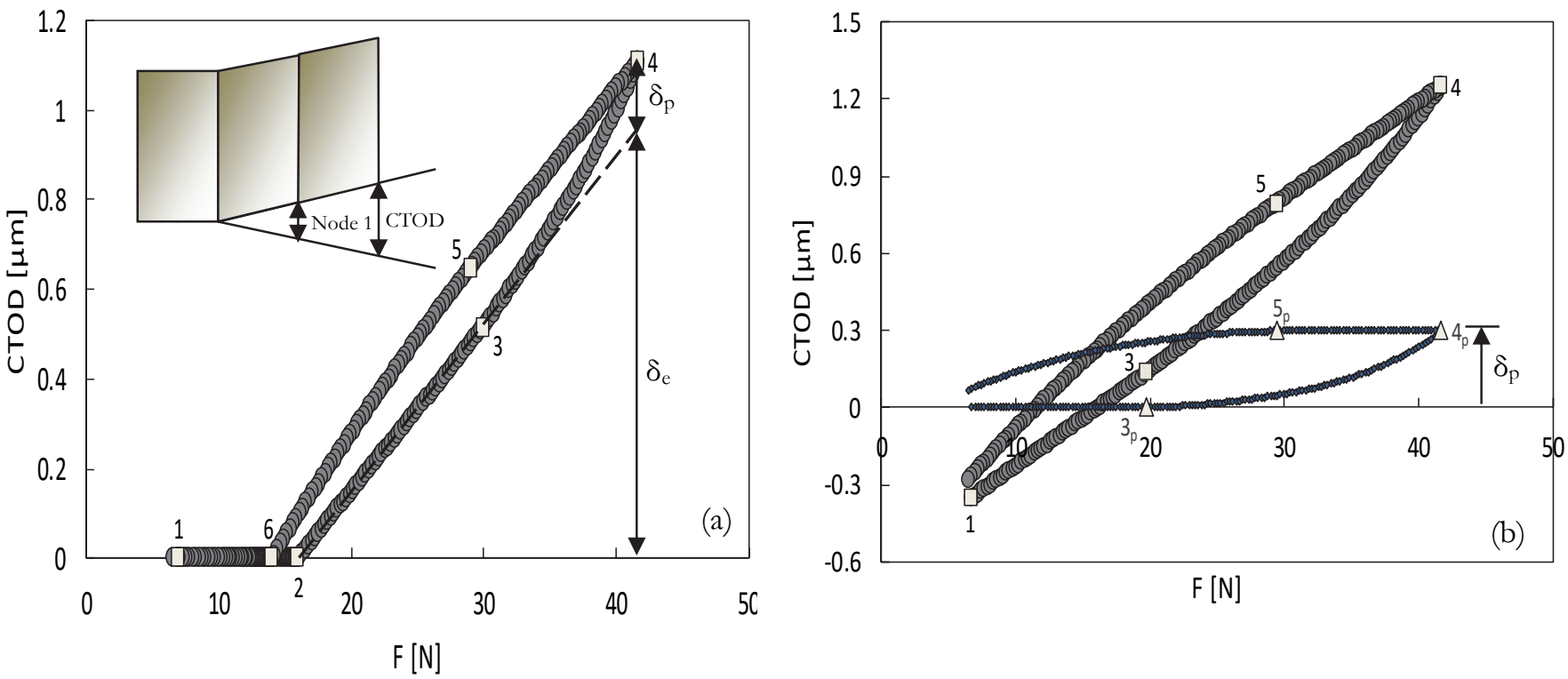

Figure 2: (a) CTOD versus load with contact; (b) CTOD and plastic CTOD versus load without contact (AA7050-T6; plane stress; $\Delta \mathrm{a}=1.272 \mathrm{~mm})$.

A CTOD versus force curve in a simulation without contact at the crack flanks is illustrated at Fig. 2b. Simulations with no contact at the crack flanks are not physically possible but can be processed in numerical studies. The artificial removal of the contact is particularly interesting because it isolates the results from the effect of crack closure. The points represented in this curve, are identical to the ones with contact. The simulation starts at point 1 and the crack opens at this minimum load, therefore comparing with the previous figure, points 1 and 2 are coincident. At point 3 , the tip enters the elastic-plastic regime and crack opens progressively until point 4 where the maximum load is reached. In stretch 4-1, begins the discharge with elastic deformation happening first, followed by plastic deformation. The separation of regimes occurs at point 5 .

Fig. $2 \mathrm{~b}$ also plots the plastic CTOD versus load. As can be seen, before the transition point, $3_{\mathrm{p}}$, there is no plastic deformation. After that, occurs a quick increase of the plastic deformation with the increase of applied load, reaching the maximum value at $4_{p}$. The rate of variation of plastic deformation increases up to the maximum load, which means that deformation is progressively easier. Between $4_{\mathrm{p}}$ and $5_{\mathrm{p}}$, the plastic deformation remains constant as the load applied decreases, because as already mentioned, in this stretch only elastic deformation occurs. 
Effect of $Y_{0}$ without contact of crack flanks

The contact between crack flanks can be avoided numerically, which is very interesting because it eliminates the crack closure phenomenon, as already mentioned. Therefore, the effect of material's yield stress can be studied singly. Variations of the yield stress (cases "0.75Y0", "Ref" and "1.25Y0", in Fig. 3) were made to compare different curves of CTOD and plastic CTOD versus load in simulations without contact. The curves are shown in Fig. 3 (a) and (b). From Fig. 3(a), as can be seen, the curves start apart and tend to approach for higher loads. The slope in the elastic regime is almost the same for the three situations. This is logical since this regime is greatly dependent on Young's modulus, which is not changed. An increase of the yield stress causes the material to enter the plastic regime for higher values of load and less plastic CTOD range is achieved, as it is shown in Fig. 3(b). In other words, as expected, the elastic regime (i.e., the region between points 2 and 3 in Fig. 2) extends with the increase of material's yield stress. It was also found that these curves were almost overlapped for SS304L.
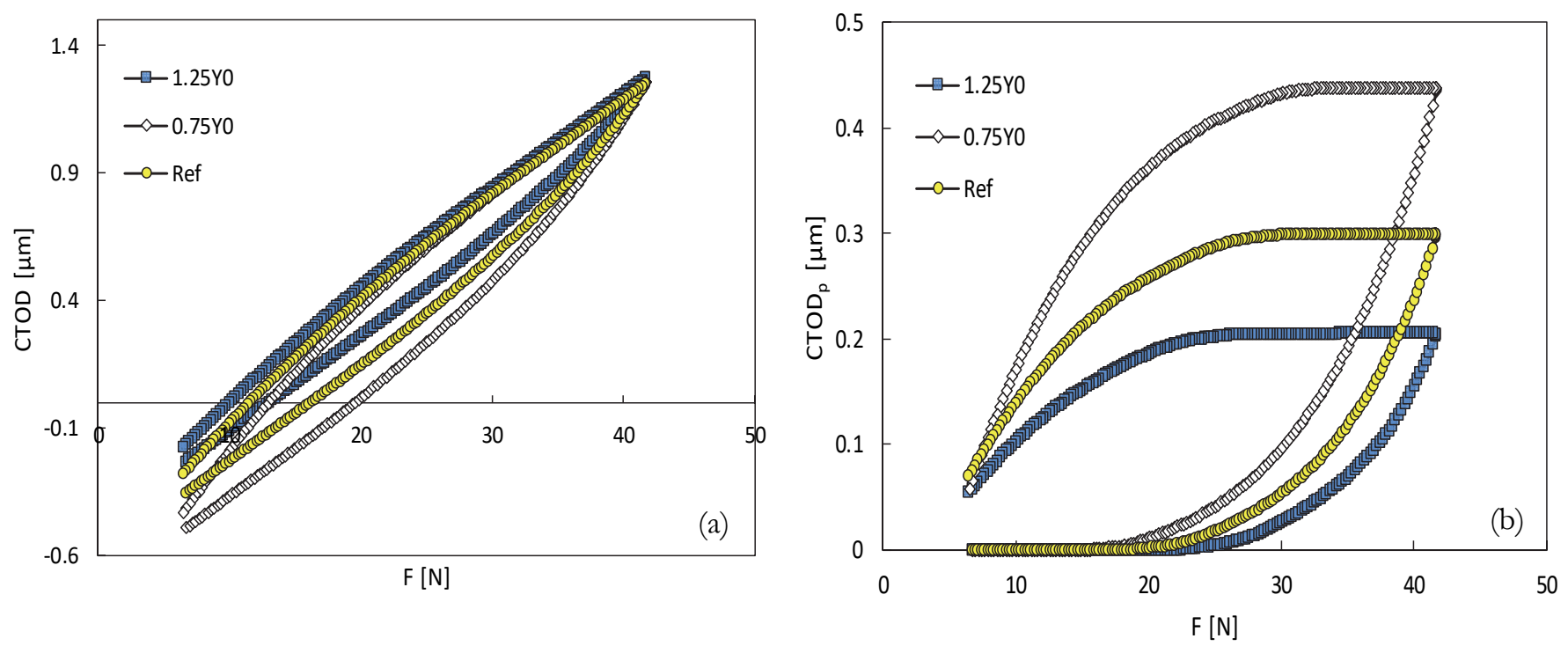

Figure 3: (a) CTOD versus load; (b) plastic CTOD versus load (AA7050-T6; plane stress; no contact).

Fig. 4a presents the variation of plastic CTOD range, $\delta_{\mathrm{p}}$, with yield stress, $\mathrm{Y}_{0} . \delta_{\mathrm{p}}$ is intimately related with FCG, as was studied in previous works of the authors [2,3]. In this picture, points located at $0 \%$ means that the yield stress assumes the reference value. The other four points correspond to more and less $25 \%$ and $50 \%$ of the elastic limit, as indicated in Tab. 1. It is observed a decrease of plastic CTOD with the increase of the yield stress, as could be expected. Looking to the results of the AA7050, it is possible to see that the variation is non-linear, being more important at lower values of $\mathrm{Y}_{0}$. The decrease is more significant for AA7050-T6 than for the SS304L, and for this case is quite small. This indicates that the influence of $Y_{0}$ greatly depends on other material properties. Looking to Tab. 1, it is possible to see that the SS304 has a constant value of saturation stress, $\mathrm{Y}_{\text {sat }}$, therefore this parameter is probably more relevant than $\mathrm{Y}_{0}$. The analysis of the range of elastic deformation, $\delta_{\mathrm{e}}$, showed that this does not change significantly. This could be expected since this deformation greatly depends on Young's modulus, which was kept constant.

Fig. 5a shows stress-strain curves for a Gauss Point located at a distance of $1.184 \mathrm{~mm}$ from the initial crack tip position. The location of the Gauss Point and the successive positions of the tip are schematically shown at Fig. 5b. Since the elements have dimensions $8 \times 8 \mu \mathrm{m}^{2}, 148 \mathrm{crack}$ increments were performed. As it is shown, the effect of the variation on the yield stress can be seen since the first cycle, where for a fixed value of plastic deformation, the increase of the elastic limit causes an increase of the stress required to achieve that value of deformation. The plastic deformation in the first cycle also indicates that the Gauss Point is inside the first monotonic plastic zone. As the crack propagation occurs, the range of stresses increases, causing more deformation. Compressive stresses increase in magnitude, beginning to produce inverse deformation. The largest values of stress happen when the Gauss Point is immediately ahead of the crack tip. The two load cycles applied between crack increments are now clearly visible. Larger values of plastic deformation are achieved for the reference curve which has a lower yield stress, as was expected. 


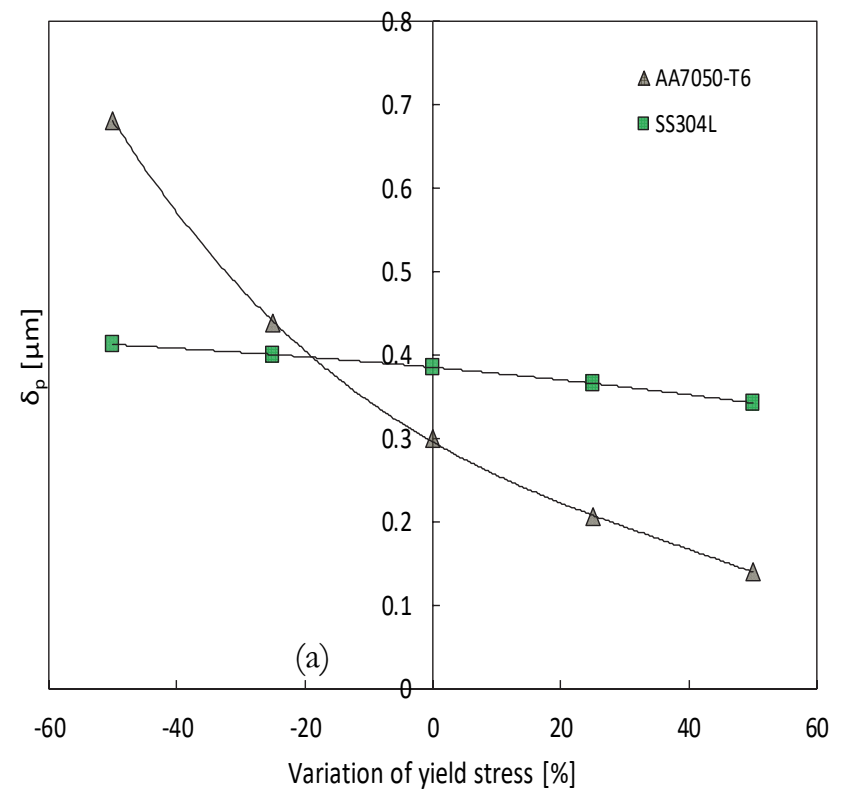

Figure 4: (a)Plastic CTOD range, $\delta_{\mathrm{p}}$, versus the variation of the yield stress relative to the reference value in percentage, (plane stress; No contact).
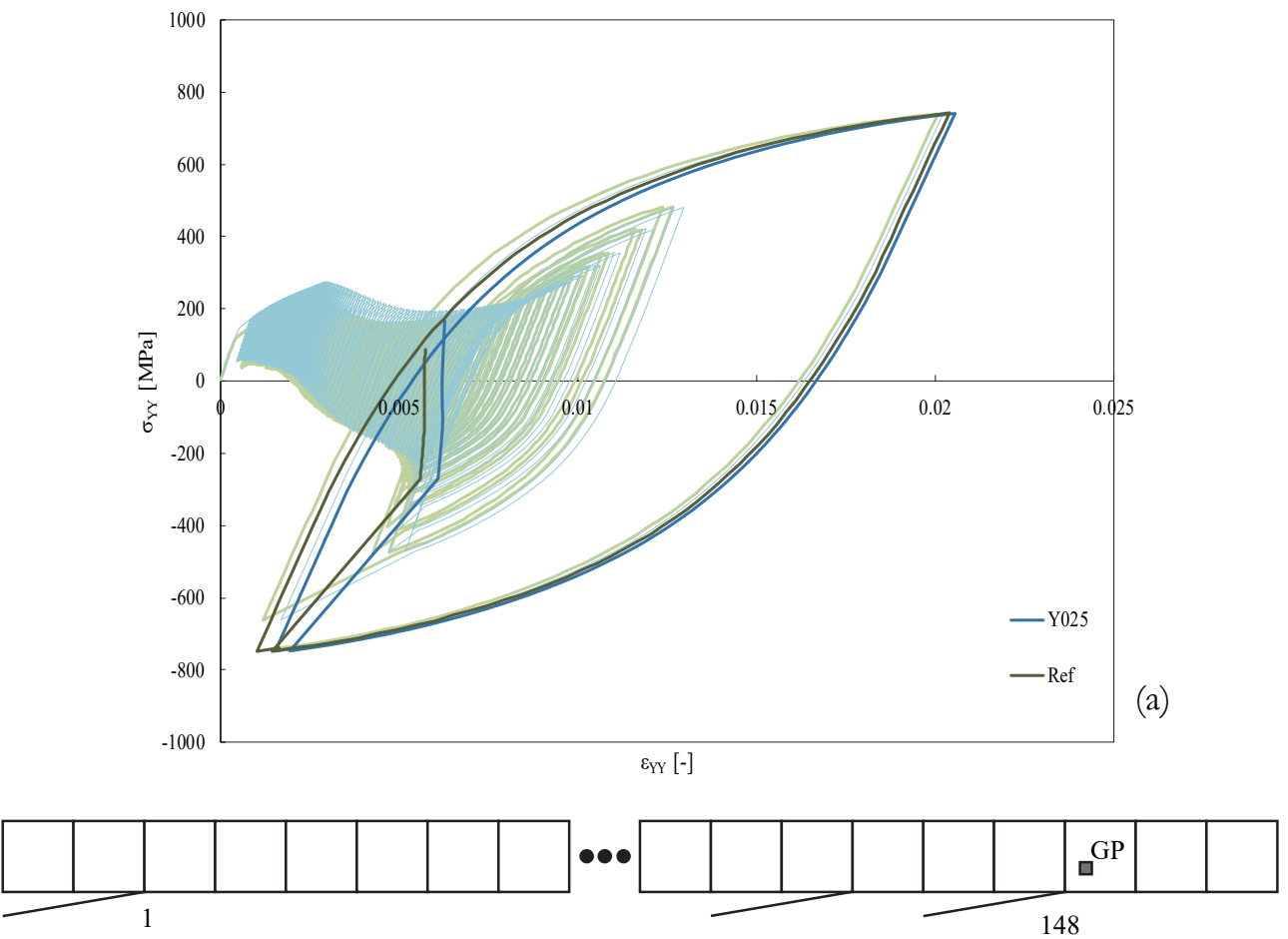

Figure 5: (a) Stress-strain curves for the reference value of the yield stress and 1.25 times that value (b) Schematic representation of Gauss point, at a distance of $1.184 \mathrm{~mm}$ ahead of the initial crack tip position, and crack growth (SS304L; plane stress; no contact).

Figs. 6a and 6b plot load above onset of plastic deformation versus CTODp for SS304L and AA7050, respectively, in plane stress conditions. The objective is to study the material hardening at the crack tip, as a function of the yield stress. Further increases in load are required to increase the plastic CTOD. Also, the rate of variation of plastic CTOD increases with the decrease of the yield stress. The curves are nearly coincident for lower values of applied load in SS304L, which 
means that in these conditions, for a fixed value of the load, a variation in the yield stress practically does not change the plastic CTOD. This is according the results of Fig. 4. The separation of the curves is more prominent for the AA7050 and this effect begins to be seen in lower values of applied loads.
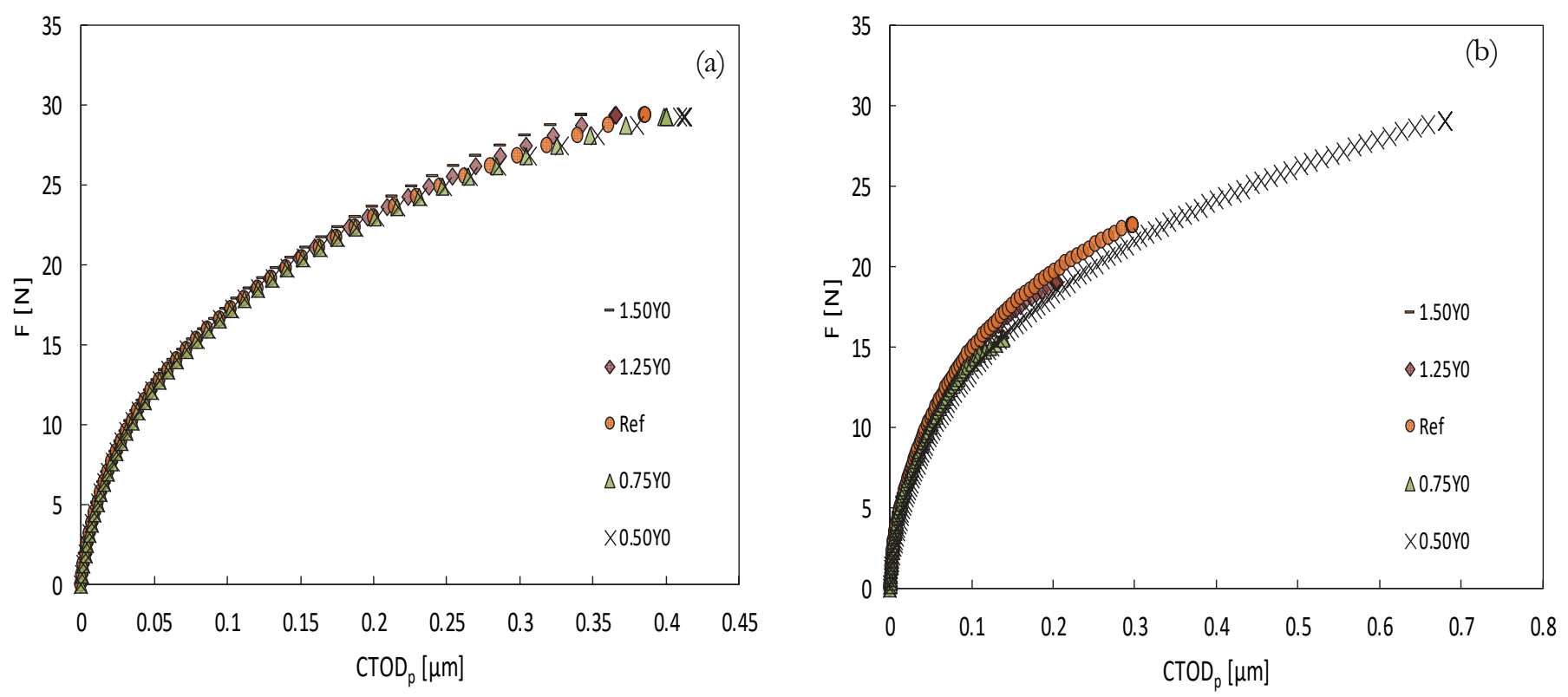

Figure 6: Load versus plastic CTOD. (a) SS304L; plane stress; (b) AA7050-T6; plane stress (without contact).
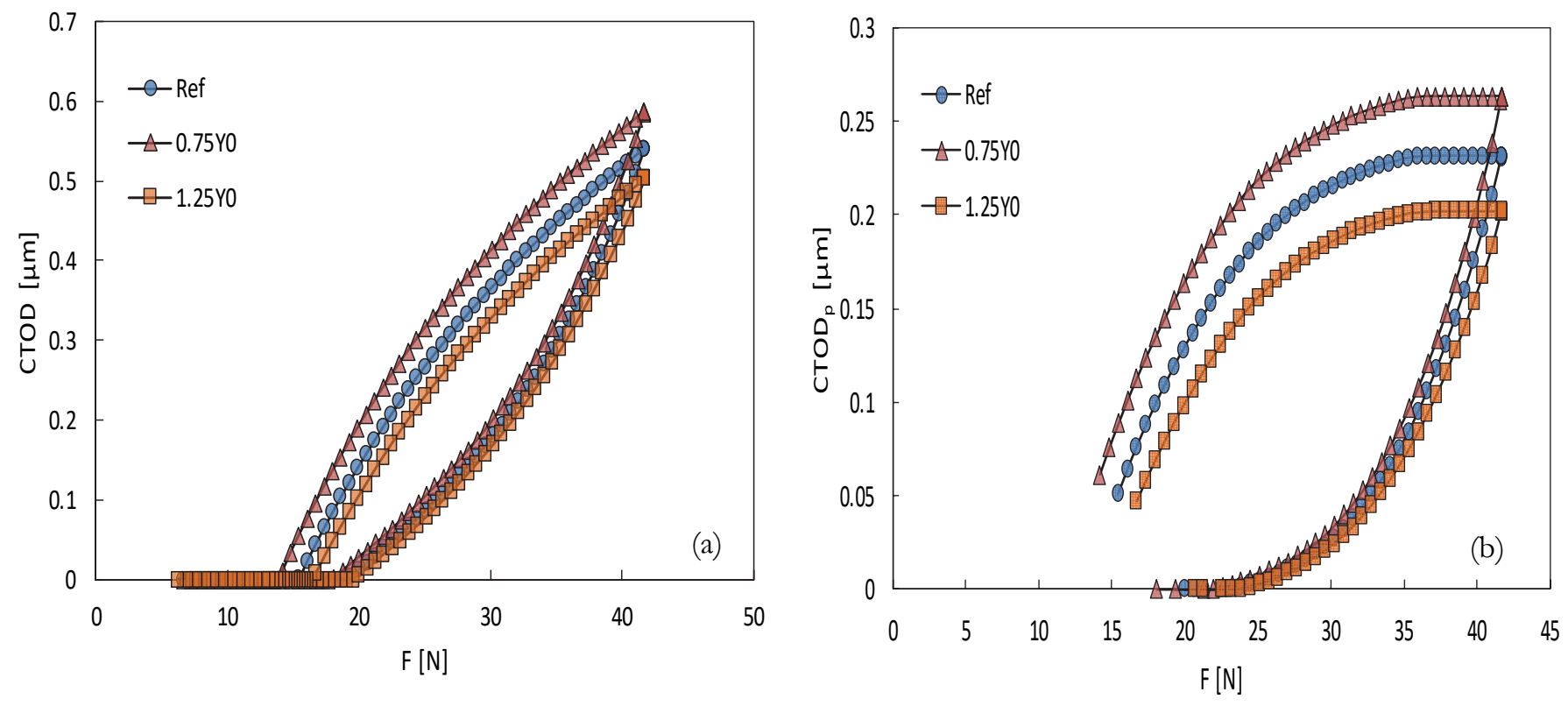

Figure 7: (a) CTOD versus load; (b) plastic CTOD versus load (AA7050-T6; plane stress; contact)

\section{Effect of crack closure}

Three curves of CTOD versus applied load were plotted in a graph shown in Fig. 7a. Each curve corresponds to one value of initial yield stress which took the following values: $87.75 \mathrm{MPa}, 117 \mathrm{MPa}$, and 146.25 MPa. As can be seen, the increase of yield stress for a constant load range causes a reduction of the CTOD, and higher crack opening and closure levels. The curves are almost overlapped for small values of the applied load. The separation of the curves occurs for relatively high values of load, when plastic deformation is notable, as shown in Fig. 7b, that illustrates the plastic CTOD versus the applied load, for the same cases of the previous figure. It seems to exist more discrepancy of the curves during 
unloading. Higher values of yield stress imply larger elastic regime at the crack tip, which causes the tip to enter plastic deformation for higher loads.

Fig. 8 plots $\mathrm{U}_{\text {clos }}$ versus the variation of the yield stress in percentage for the cases with contact between crack flanks. $\mathrm{U}_{\text {clos }}=\left(\mathrm{F}_{\mathrm{open}}-\mathrm{F}_{\min }\right) /\left(\mathrm{F}_{\max }-\mathrm{F}_{\min }\right)$ is the portion of the load cycle during which the crack is closed. The yield stress has a great influence on the level of crack closure for the AA7050-T6. Increasing the elastic limit from $-50 \%$ to $50 \%$ causes a $30 \%$ decrease in crack closure level. On the other hand, for the SS304L, an increase of the elastic limit from -50\% to $50 \%$ causes an increase of $10 \%$ in crack closure level. Therefore, the crack closure level seems to be also more affected by $\mathrm{Y}_{\text {sat }}$ than by $\mathrm{Y}_{0}$.

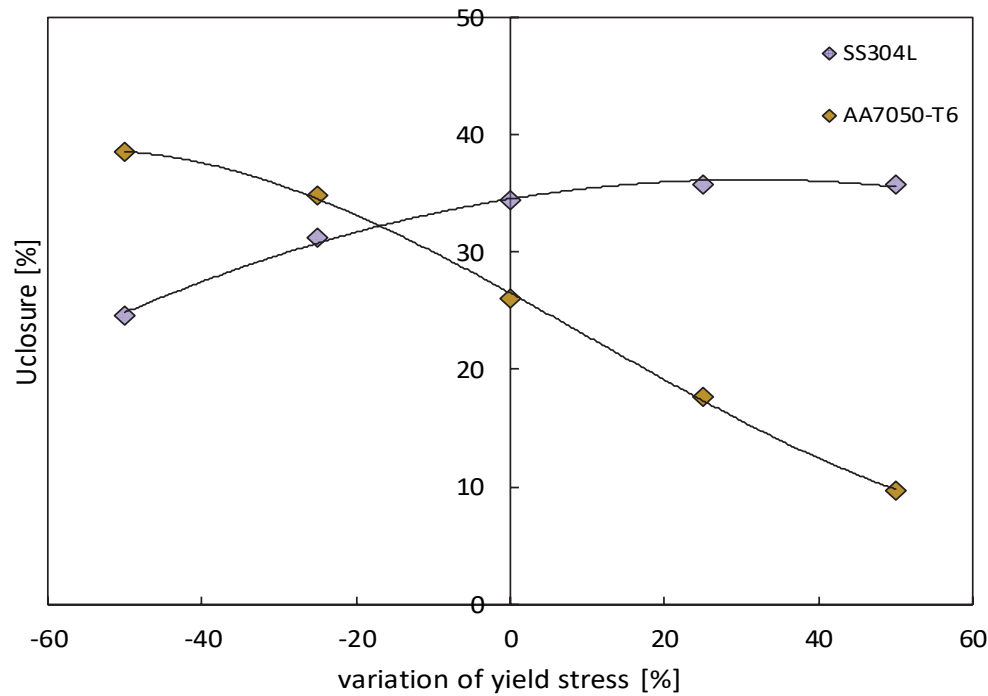

Figure 8: Crack closure versus the variation of the yield stress relative to the reference value in percentage (SS304L; plane stress and AA7050-T6; plane stress)
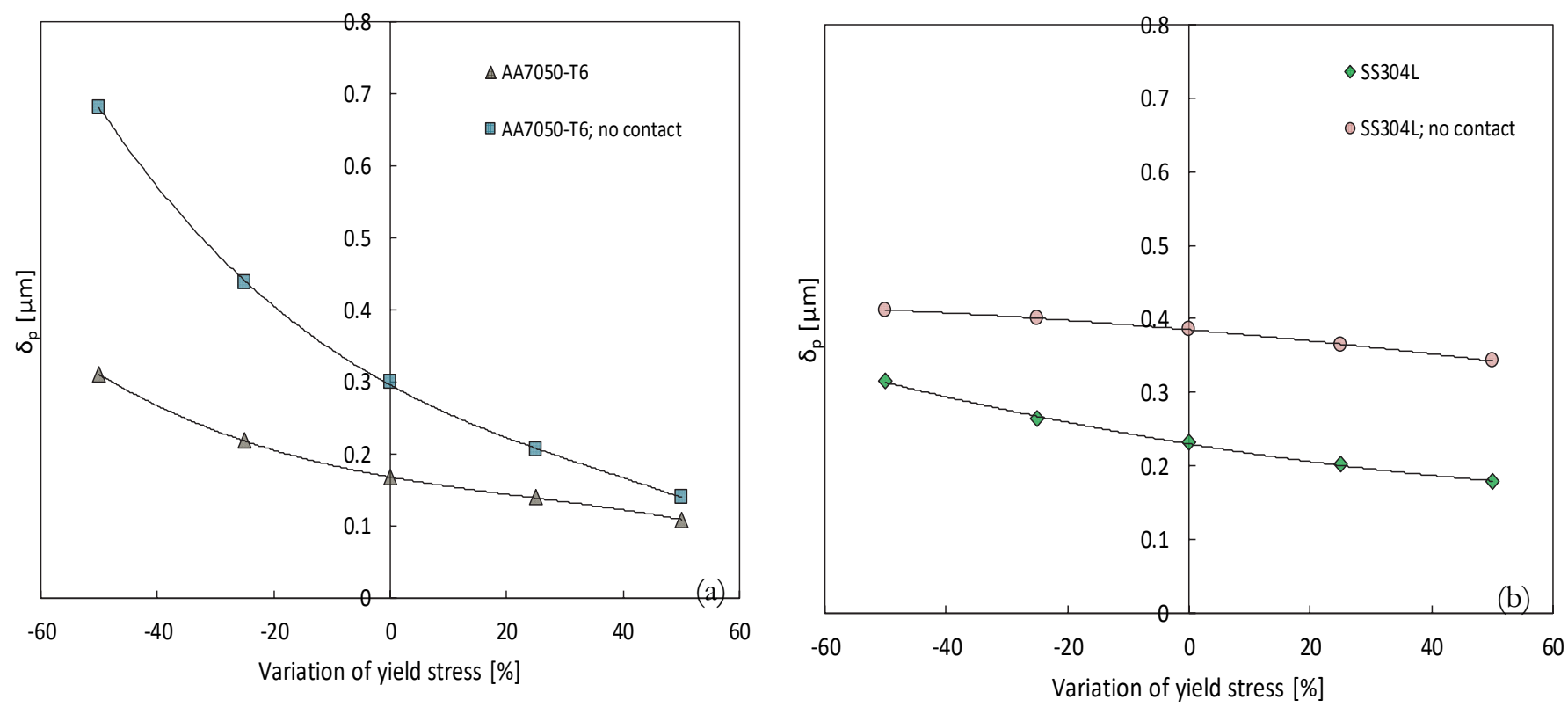

Figure 9: Plastic CTOD range, $\delta_{\mathrm{p}}$, versus the variation of the yield stress relative to the reference value in percentage (plane stress) (a) AA7050-T6; (b) SS304L.

Fig. 9 plots $\delta_{\mathrm{p}}$ versus yield stress, without and with contact of crack flanks, in order to understand the effect of crack closure phenomenon. The first aspect is that crack closure has a great influence on $\delta_{\mathrm{p}}$, and therefore on FCG rate. For the 
AA7050-T6 the decrease of $\delta_{\mathrm{p}}$ is much more evident for relatively low values of $\mathrm{Y}_{0}$. This is according Fig. 8, which shows higher values of crack closure level for lower values of $Y_{0}$. At relatively high values of $Y_{0}$, Uclos $\approx 10 \%$, i.e., is relatively small, therefore there is a minor effect on $\delta_{\mathrm{p}}$. For the $304 \mathrm{~L}$ stainless steel, the opposite trend is observed, i.e., the increase of $\mathrm{Y}_{0}$ increases the influence of crack closure, which is also according Fig. 8.
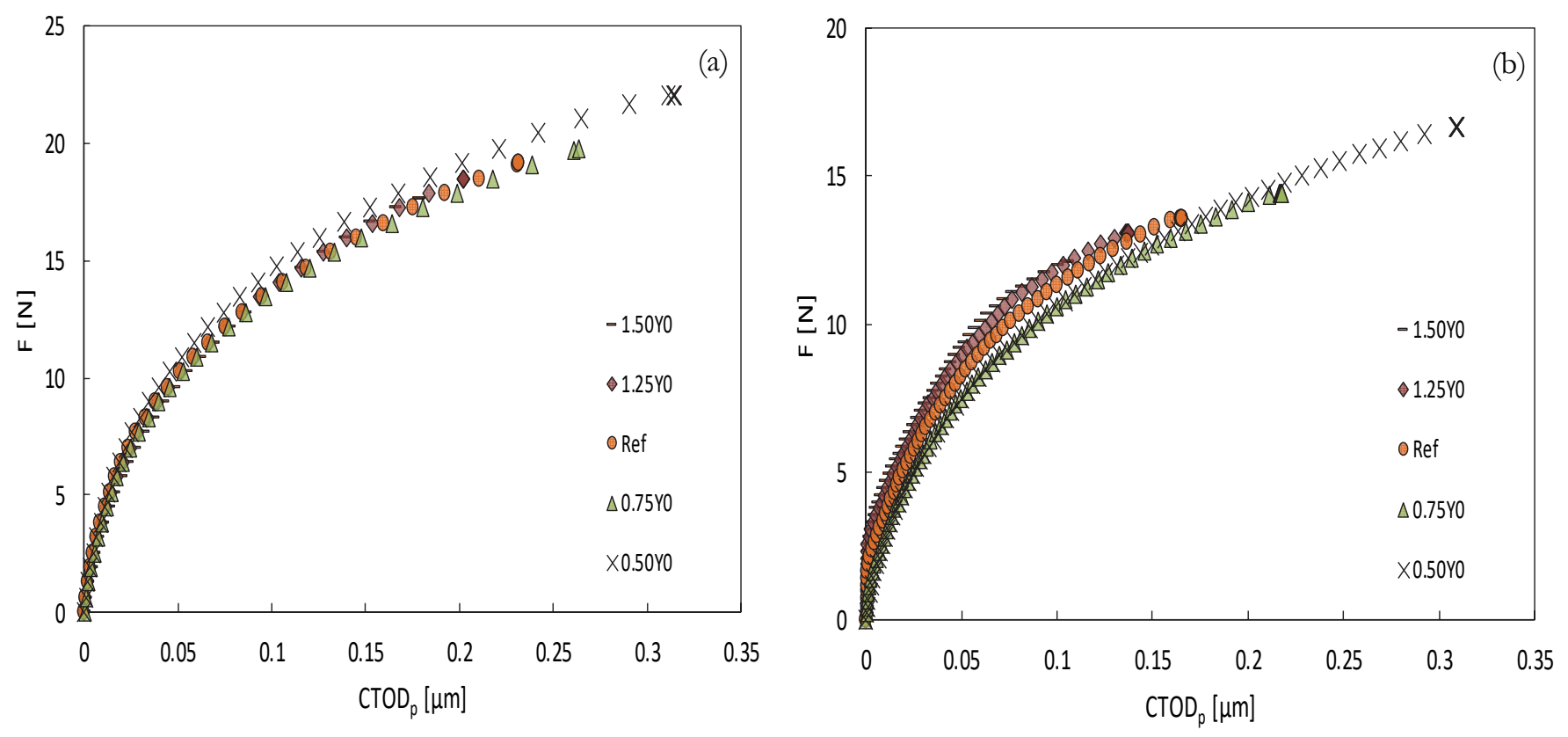

Figure 10: Load versus plastic CTOD. (a) 304L; plane stress contact; (b) AA7050-T6; plane stress with contact.

Figs. 10a and 10b plot load versus CTODp for SS304L and AA7050, respectively, in plane stress conditions. The objective is to study the material hardening at the crack tip, as a function of the yield stress. Further increases in load are required to maintain the increase in plastic CTOD. Also, the rate of variation of plastic CTOD increases with the decrease of the yield stress. The curves are nearly coincident for lower values of applied load in SS304L, which means that in these conditions, for a fixed value of the load, a variation in the yield stress practically does not change the plastic CTOD. The separation of the curves is more evident for the AA7050 and this effect begins to be seen in lower values of applied loads.

\section{Sensitivity analysis}

A sensitivity analysis was developed (see Fig. 11) to quantify the relative importance of the different material parameters. Local sensitivity analysis aims at estimating the influence of the input parameters on the output quantities in one particular point of the input parameter space [7]. The non-dimensional sensitivity of $\delta_{p}$ relatively to the different material parameters is expressed as follows:

$$
\nabla f=\frac{\partial \delta_{p}}{\partial m_{p}} \frac{m_{p}}{\delta_{p}}
$$

where $\nabla \mathrm{f}$ is the sensitivity coefficient and $m_{p}$ represents the material parameter. This analysis was made for the $304 \mathrm{~L}$ stainless steel in a simulation with no contact of crack flanks. From the analysis of the figure, it can be concluded that the yield stress of the material has a relatively low influence on plastic CTOD. The isotropic saturation stress $\left(\mathrm{Y}_{\text {sat }}\right)$ has a higher influence, similar to the influence of kinematic saturation stress $\left(\mathrm{X}_{\text {sat }}\right)$. On the other hand, even though, the Young's modulus is an elastic parameter it has a relatively high influence on plastic CTOD. 


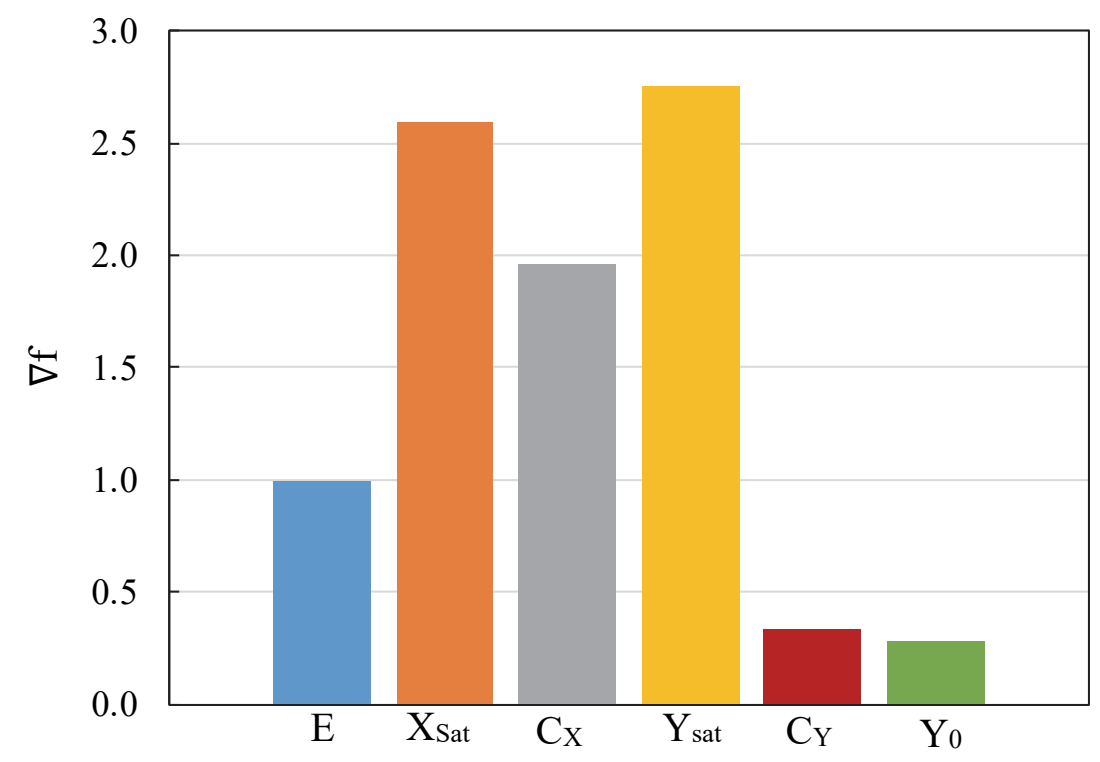

Figure 11: Sensitivity of the plastic CTOD range for Young's Modulus, kinematic hardening parameters and yield stress (SS304L; plane stress; no contact), calculated at the reference point (see Tab. 1).

\section{CONCLUSIONS}

A numerical study was developed to quantify the effect material's yield stress on plastic CTOD and therefore on fatigue crack growth rate. Two base materials were studied: the 7050-T6 aluminium alloy and the 304L stainless steel. The increase of $Y_{0}$ was found to decrease $\delta_{\mathrm{p}}$, and therefore FCG rate. The variation is non-linear, being more important for lower values of $Y_{0}$. The effect of $Y_{0}$ was found to be much more relevant for the 7050 aluminium alloy than for the 304L stainless steel, which indicates a major influence of other material properties, namely the saturation stress. With the inclusion of crack closure, the reduction of $\delta_{\mathrm{p}}$ with $\mathrm{Y}_{0}$ was kept, but there is a substantial reduction of $\delta_{\mathrm{p}}$ and therefore of FCG rate.

\section{ACKNOWLEDGEMENTS}

7 his work was financially supported by: Project PTDC/CTM-CTM/29101/2017 - POCI-01-0145-FEDER-029101 funded by FEDER funds through COMPETE2020 - Programa Operacional Competitividade e Internacionalização (POCI) and by national funds (PIDDAC) through FCT/MCTES.

\section{REFERENCES}

[1] Antunes, F.V., Branco, R. Prates, P.A. and Borrego, L. (2017) Fatigue crack growth modelling based on CTOD for the 7050-T6 alloy, Fatigue Fract Engng Mater Struct, 40, pp. 1309-1320.

[2] Antunes, F.V., Ferreira, M.S.C., Branco, R., Prates, P., Gardin, C. and Sarrazin-Baudoux, C. (2019). Fatigue crack growth versus plastic CTOD in the 304L stainless Steel, Engineering Fracture Mechanics, 214, pp. 487-503.

[3] Antunes, F.V., Branco, R., Prates, P.A. and Borrego, L. (2017). Fatigue crack growth modelling based on CTOD for the 7050-T6 alloy, Fatigue Fract Engng Mater Struct, 40, pp. 1309-1320.

[4] Menezes, L.F. and Teodosiu, C. (2000). Three-dimensional numerical simulation of the deep-drawing process using solid finite elements, J Mater Process Technol., 97(1-3), pp. 100-106. 
[5] Oliveira, C., Alves, J.L. and Menezes, LF. (2008). Algorithms and strategies for treatment of large deformation frictional contact in the numerical simulation of deep drawing process, Archiv Comput Methods Eng., 15(2), pp. 113162.

[6] Neto, D.M., Oliveira, M.C., Menezes, L.F., Alves, J.L. (2014) Applying Nagata patches to smooth discretized surfaces used in 3D frictional contact problems, Comput Methods Appl Mech Eng., 271, pp. 296-320.

[7] Tortorelli, D. and Michaleris, P. (1994). Design sensitivity analysis: overview and review, Inverse problems in Engineering, 1, pp. 71-105. 